\title{
FAKTOR-FAKTOR YANG BERHUBUNGAN DENGAN MUNCULNYA KEMBALI PENYAKIT KAKI GAJAH DI KABUPATEN ACEH BARAT TAHUN 2018
}

\section{FACTORS RELATED TO RE-EMERGING DISEASE OF FILARIASIS IN WEST ACEH DISTRICT 2018}

\author{
Danvil Nabela ${ }^{1}$, Hermansyah $^{2}$, Nizam Ismail ${ }^{3}$ \\ ${ }^{1}$ Program Studi Magister Kesehatan Masyarakat, Pascasarjana Universitas Muhammadiyah Aceh \\ 2,3Pascasarjana Universitas Muhammadiyah Aceh, Banda Aceh 23245 \\ Universitas Muhammadiyah Aceh \\ *email: danvilmilanisti91@gmail.com
}

\begin{abstract}
ABSTRAK
Filariasis merupakan penyakit infeksi yang disebabkan oleh cacing filaria jika tidak cepat maka akan mengalami cacat permanen, ketika dalam kondisi kronik terjadi pembengkakan pada kaki dan tangan yang disebut elephantiasis (kaki gajah). Kabupaten Aceh Barat merupakan salah satu kabupaten bagian barat selatan yang memiliki jumlah kasus filariasis yang terus mengalami peningkatan dari 9 kasus di tahun 2015 menjadi 15 kasus pada tahun 2017. Banyak faktor yang diduga sebagai penyebab kejadian penyakit kaki gajah diantaranya pengetahuan, perilaku, lingkungan fisik rumah, dan sosialisasi penyuluhan petugas kesehatan. Tujuan penelitian untuk mengetahui faktor-faktor yang berhubungan dengan munculnya kembali penyakit kaki gajah di Kabupaten Aceh Barat tahun 2018. Penelitian ini bersifat kuantitatif untuk mengetahui risiko penyakit kaki gajah dengan menggunakan Matched Case Control sampel dalam penelitian ini adalah total populasi dengan menggunakan perbandingan 1:3 maka jumlah sampel dalam penelitian ini adalah 60 orang yang terdiri dari 15 orang kasus dan 45 orang sebagai kontrol. Hasil penelitian menunjukkan bahwa munculnya kembali penyakit kaki gajah di Kabupaten Aceh Barat dengan variabel pengetahuan $(\mathrm{p}=0,021)$, sikap $(\mathrm{p}=0,042)$, tindakan $(\mathrm{p}=0,028)$, sosialisasi penyuluhan tenaga kesehatan $(\mathrm{p}=0,002)$, dan lingkungan fisik rumah $(\mathrm{p}=0,002)$ namun tidak ada hubungan dengan jenis kelamin $(\mathrm{p}=0,866)$ dan literasi kesehatan $(\mathrm{p}=0,0773)$. Faktor yang paling dominan adalah tindakan pencegahan penyakit kaki gajah yang kurang baik, dengan kecenderungan sebesar 28 kali untuk meningkatkan munculnya kembali penyakit kaki gajah lebih besar dibandingkan dengan variabel lain. Pemerintah daerah dapat mengaktifkan kembali program gotong royong pada setiap desa, dan untuk Dinas Kesehatan Aceh Barat, Kepala Puskesmas dapat mempromosikan pencegahan filariasisi menggunakan media leaflet atau poster yang dipasang ditempat-tempat umum di desa dan tempat strategis lainnya, seperti papan informasi, pos siskamling dan balai desa di wilayah Aceh Barat
\end{abstract}

Kata Kunci: Filariasis, Elephantiasis, penyakit kaki gajah.

\section{ABSTRACT}

Filariasis is an infectious disease caused by filaria worms if it is not fast it will experience permanent disability, when in chronic conditions swelling of the feet and hands is called elephantiasis (elephantiasis). West Aceh Regency is one of the south west districts that has a number of cases of filariasis that continues to increase from 9 cases in 2015 to 15 cases in 2017. Many factors are suspected as causes of elephantiasis including knowledge, behavior, physical environment of the home, and information dissemination on health workers. The purpose of this study was to determine the factors associated with the re-emergence of elephantiasis in the West Aceh District in 2018. This research is quantitative to determine the risk of elephantiasis by using Matched Case Control The sample in this study is the total population using a ratio of $1: 3$, the number of samples in this study were 60 people consisting of 15 cases and 45 people as controls. The results showed that the reappearance of 
elephantiasis in West Aceh District with knowledge varibale $(p=0,021)$, attitude $(p=0,042)$, actions $(p=0,028)$, socialization of health education counseling $(p=0,002)$, and the physical environment of the home $(p 0,002)$ but there was no relationship with sex $(p=0,866)$ and health literacy $(p=0,0773)$. The most dominant factor is an unfavorable preventive measure for elephantiasis, with a tendency of 28 times to increase re-emergence of elephantiasis more than other variables. Local governments can reactivate the mutual assistance program in each village, and for the West Aceh Health Service, the Head of the Puskesmas can promote the prevention of filariasis using media leaflets or posters installed in public places in the village and other strategic locations, such as information boards, siskamling posts and village hall in the West Aceh region.

Keywords: Re-emerging disease, Elephantiasis, elephantiasis disease

\section{PENDAHULUAN}

Filariasis atau Elephantiasis (penyakit kaki gajah) merupakan penyakit menular menahun yang disebabkan oleh cacing filaria dan ditularkan oleh semua jenis nyamuk. Cacing tersebut hidup di saluran dan kelenjar getah bening dengan manifestasi klinik akut berupa demam berulang, peradangan saluran kelenjar getah bening. Pada stadium lanjut dapat menimbulkan cacat menetap berupa pembesaran kaki, lengan, payudara dan alat kelamin. Tiga spesies cacing filaria penyebab filariasis limfatik adalah Wuchereria bancrofti, Brugia malayi dan Brugia timor. ${ }^{1}$

Penyakit kaki gajah merupakan penyakit zoonosis menular yang banyak ditemukan di wilayah tropika seluruh dunia. Filariasis ditemukan di daerah Asia, Afrika, Amerika Tengah, dan Selatan, dengan 120 juta manusia terjangkit. ${ }^{2}$ Penyakit menular di Indonesia masih berperan sebagai penyebab morbilitas dan mortalitas, filariasis salah satu penyakit endemis yang diprioritaskan oleh Pemerintah Indonesia untuk dieliminasi. ${ }^{3}$
Filariasis di Indonesia pertama kali dilaporkan oleh Haga dan Van Eecke pada tahun 1889 di Jakarta yaitu dengan ditemukannya penderita filariasis skrotum. Pada saat itu pula Jakarta diketahui endemik filariasis limfatik yang disebabkan oleh Wuchereria bancrofti. Lebih dari 1,4 milyar orang di 73 negara beresiko terinfeksi cacing filariasis. Kira-kira $65 \%$ yang terinfeksi berada di wilayah Asia Tenggara, 30\% di wilayah Afrika, dan sisanya berada di daerah tropis. Filariasis limfatik menyebabkan lebih dari 25 juta laki-laki dengan gangguan genital dan lebih dari 15 juta orang dengan limfodema. ${ }^{4}$

Penyakit ini merupakan salah satu masalah kesehatan masyarakat yang serius di Indonesia. Mayoritas wilayah Indonesia merupakan daerah endemis filariasis, wilayah paling tinggi prevalensi filariasis yaitu Indonesia Timur, hal itu dapat dilihat dari hasil survei filariasis pada tahun 2009 dari 472 kabupaten/ kota se-Indonesia, 337 kabupaten/ kota merupakan wilayah endemis. Tahun 2003-2008 terdapat peningkatan yang sangat 
tinggi. Pada tahun 2003 jumlah kasus yang dilaporkan sebanyak 6720 kasus dan pada tahun 2008 meningkat menjadi 11.699 kasus. Tahun 2009 diprediksi penduduk berisiko tertular filariasis mencapai lebih dari 125 juta jiwa dengan 11.914 kasus dan diestimasikan prevalensi mikrofilaria 19\%, kurang lebih penyakit ini akan mengenai 40 juta penduduk. ${ }^{5}$

Kasus filariasis diseluruh wilayah Indonesia mempunyai tingkat endemisitas yang tinggi, kasus filariasis pada tahun 2015: 13.032 kasus, dibandingkan dengan tahun 2014 sebanyak 14.932 kasus. Dari kasus tersebut kasus klinis filariasis terbanyak yaitu Nusa Tenggara Timur sebanyak 2.864 kasus, Aceh (2.372 kasus), dan Papua Barat (1.244 kasus). Sedangkan Provinsi dengan kasus filariasis terendah adalah Kalimantan utara (11 kasus), NTB (14 Kasus) dan Bali (18 kasus). ${ }^{6}$

Kasus filariasis di Aceh sebesar 2.372 kasus, kabupaten tertinggi ada pada kabupaten Aceh Utara 1.353 kasus, Kabupaten Pidie 84 kasus, Kabupaten Aceh Timur 67 kasus Kabupaten Aceh Besar 50 kasus, Aceh Selatan dan Aceh Tamiang 42 kasus, kota Lhokseumawe 18 kasus.

Kabupaten Aceh Barat merupakan salah satu kabupaten yang memiliki jumlah kasus filariasis terbanyak di daerah pesisir barat selatan. Pada tahun 2015, jumlah kasus filariasis sebanyak 9 kasus, sedangkan pada tahun 2016 sebanyak 11 kasus dan pada tahun 2017 sebanyak 15 kasus. Banyak faktor risiko yang mampu memicu timbulnya kejadian filariasis, beberapa di antaranya adalah faktor lingkungan. Faktor lingkungan merupakan salah satu yang mempengaruhi kepadatan vektor filariasis. Lingkungan ideal bagi nyamuk dapat dijadikan tempat potensial untuk perkembangbiakan dan tempat istirahat nyamuk sehingga kepadatan nyamuk akan meningkat. ${ }^{7}$

Perilaku manusia menjadi faktor yang menentukan seseorang akan terjangkitnya penyakit filariasis sebab sebagus apapun program yang dilakukan oleh Pemerintah tanpa peran aktif masyarakat dalam program liminasi filariasis tidak akan mencapai hasil yang diharapkan. ${ }^{8}$ Perilaku kesehatan merupakan kegiatan individu yang berkaitan dengan pemeliharaan dan peningkatan kesehatan. Pemeliharaan kesehatan berupa meningkatkan derajat kesehatan individu dengan melakukan usaha pencegahan atau melindungi diri sehingga terhindar dari penyakit. ${ }^{9}$

Perilaku kesehatan, yang dalam hal ini partisipasi masyarakat dalam program kesehatan dipengaruhi oleh karakteristik manusia itu sendiri, lingkungan kondusif yang memungkinkan tumbuhnya partisipasi meliputi norma, keberadaan institusi lokal, dukungan tokoh masyarakat, dan pelayanan kesehatan yang memberikan pendidikan kesehatan melalui penyuluhan. ${ }^{10}$

Faktor risiko selanjutnya adalah kebiasaan keluar rumah pada malam hari dan kebiasaan tidak menggunakan kelambu saat tidur. Pengetahuan seseorang/ individu mengenai filariasis sehingga membuat 
kesadaran seseorang meningkat masuk ke dalam faktor risiko yang harus diperhatikan. ${ }^{11}$

Indonesia telah melakukan

kesepakatan bahwa filariasis harus di eliminasikan pada tahun 2020 dengan menggunakan metode yang sama dengan negara negara yang endemis filariasis yaitu Global Elimination of Lymphatic Filariasis (GELF) dengan menggunakan strategi mencakup pemutusan rantai penularan filariasis melalui Pemberian Obat Pencegah Massal (POPM) dengan menggunakan Diethylcarbamazine Citrate (DEC) yang dikombinasikan dengan albendazole sekali setahun minimal 5 tahun dan upaya mencegah dan membatasi kecacatan dengan penataan kasus klinis filariasis baik kasus akut maupun kronis. ${ }^{6}$

Penelitian ini dilakukan pada daerah yang statusnya tidak atau belum menjadi daerah endemis filariasis. Meskipun wilayah tersebut belum ditetapkan sebagai daerah endemis, namun informasi mengenai aspek penentu penularan filariasis dalam hubungannya dengan parasit, vektor dan manusia di wilayah tersebut masih sangat minim, dampak jika filariasis tidak ditanggulangi yaitu akan semakin luas penularan dan akan menjdi wabah sehingga diperlukan studi mengenai hal tersebut. Hal ini penting untuk diketahui agar dapat digunakan oleh berbagai pihak yang terkait dalam rangka mendukung program eliminasi filariasis sebagaimana konsekuensi kesepakatan global dalam GELF. ${ }^{12}$

\section{METODOLOGI PENELITIAN}

Penelitian ini menggunakan penelitian kuantitatif untuk mengetahui risiko penyakit kaki gajah dengan menggunakan Matched Case Control.

Populasi kasus dalam penelitian ini adalah orang yang menderita kaki gajah di wilayah Kabupaten Aceh Barat. Data dari Dinas Kesehatan Kabupaten Aceh Barat pada tahun 2017-2018 berjumlah 15 orang. Populasi kontrol dalam penelitian ini adalah orang yang tidak menderita penyakit kaki gajah (filariasis). Sebaran sampel kontrol diwilayah Aceh Barat pengambilan kontrol yaitu responden yang menjadi tetangga dari kasus. Kriteria kontrol agar macthing (sebanding) dengan kasus maka umur disamakan. Mengingat populasi $(\mathrm{N})$ yaitu penderita filariasis < 100 maka sampel dalam penelitian ini adalah total populasi dengan menggunakan perbandingan 1:3 maka jumlah sampel dalam penelitian ini adalah 60 orang yang terdiri dari 15 orang kasus dan 45 orang sebagai kontrol. ${ }^{13}$ 


\section{HASIL}

\section{Karakteristik Responden}

Tabel 1. Gambaran karakteristik responden berdasarkan jenis kelamin, umur, dan pendidikan di Kabupaten Aceh Barat Tahun 2018 (n=60)

\begin{tabular}{|c|c|c|c|c|c|}
\hline & \multirow{2}{*}{ KARAKTERISTIK } & \multicolumn{2}{|c|}{ Kasus $(n=15)$} & \multicolumn{2}{|c|}{ Kontrol $(n=45)$} \\
\hline & & $\mathbf{F}$ & $\%$ & $\mathbf{f}$ & $\%$ \\
\hline \multirow{4}{*}{ Umur } & Usia produktif (17-55tahun & 1 & 6,67 & 3 & 6,67 \\
\hline & Pra Lansia (56-59 tahun) & 7 & 46,67 & 21 & 46,67 \\
\hline & Lansia (60-69 tahun) & 4 & 26,67 & 12 & 26,67 \\
\hline & Lansia Tua (70 tahun) & 3 & 20 & 9 & 20 \\
\hline \multirow{6}{*}{ Pendidikan } & Total & 15 & 100 & 45 & 100 \\
\hline & SD & 5 & 33,33 & 5 & 11,11 \\
\hline & SMP & 5 & 33,33 & 12 & 26,67 \\
\hline & SMA & 3 & 20 & 23 & 51,11 \\
\hline & Perguruan tinggi & 2 & 13,33 & 5 & 11,11 \\
\hline & Total & 15 & 100 & 45 & 100 \\
\hline
\end{tabular}

Sumber: Data Primer diolah tahun 2018

Tabel 1 menunjukkan bahwa proporsi responden yang katagori pra lansia lebih besar dari pada katagori umur lainnya dengan persentase $46,57 \%$ dan proporsi responden paling banyak tingkat pendidikan yaitu tingkat

\section{Hasil Analisa Univariat}

Analisis univariat ini dilakukan untuk memberikan gambaran secara deskriptif masing-masing variabel yang digunakan pada penelitian. $^{14}$ pendidikan SD dengan persentase $33,33 \%$.

Tabel 2. Frekuensi dan persentase subyek penelitian berdasarkan variabel dependen dan independen di Kabupaten Aceh Barat $(\mathbf{n}=60)$

\begin{tabular}{|c|c|c|}
\hline Variabel & Frekuensi & Persentase \\
\hline \multicolumn{3}{|l|}{ Penderita } \\
\hline Penderita kaki gajah & 15 & 25 \\
\hline Bukan penderita & 45 & 75 \\
\hline Jumlah & 60 & 100 \\
\hline \multicolumn{3}{|l|}{ Jenis kelamin } \\
\hline Perempuan & 33 & 55 \\
\hline Laki-laki & 27 & 45 \\
\hline Jumlah & 60 & 100 \\
\hline \multicolumn{3}{|l|}{ Tingkat Pengetahuan } \\
\hline Baik & 33 & 55 \\
\hline Kurang Baik & 27 & 45 \\
\hline Jumlah & 60 & 100 \\
\hline \multicolumn{3}{|l|}{ Sikap } \\
\hline Positif & 36 & 56,7 \\
\hline Negatif & 24 & 43,33 \\
\hline Jumlah & 60 & 100 \\
\hline \multicolumn{3}{|l|}{ Tindakan } \\
\hline Baik & 45 & 75 \\
\hline Kurang Baik & 15 & 25 \\
\hline
\end{tabular}




\begin{tabular}{|c|c|c|}
\hline Variabel & Frekuensi & Persentase \\
\hline \multicolumn{3}{|l|}{ Literasi kesehatan } \\
\hline Baik & 26 & 43,33 \\
\hline Kurang Baik & 34 & 56,67 \\
\hline Jumlah & 60 & 100 \\
\hline \multicolumn{3}{|c|}{ Sosialisasi Oleh Petugas Kesehatan } \\
\hline Baik & 42 & 70 \\
\hline Kurang Baik & 18 & 30 \\
\hline Jumlah & 60 & 100 \\
\hline Lingkungan Fisik Rumah & & \\
\hline Memenuhi Syarat & 31 & 51,67 \\
\hline Tidak Memenuhi Syarat & 29 & 48,33 \\
\hline Jumlah & 60 & 100 \\
\hline
\end{tabular}

Dari Tabel 2 di atas, analisis univariat menjelaskan bahwa proporsi responden positif penyakit kaki gajah $25 \%$, responden dengan pengetahuan kurang baik $45 \%$, responden memiliki sikap negatif $43,33 \%$, responden dengan tindakan pencegahan kurang baik $25 \%$, responden yang memiliki literasi kesehatan kurang baik 56,67\%, responden yang mendapatkan sosialisasi kesehatan kurang baik
$30 \%$, responden dengan lingkungan fisik rumah tidak memenuhi syarat $48,33 \%$.

\section{Hasil Analisis Bivariat}

Analisis Bivariat untuk mengetahui hubungan secara kasar antara variabel independen dengan variabel dependen tanpa mempertimbangkan variabel independen atau faktor risiko lainnya. ${ }^{14}$

Tabel 3. Faktor-faktor yang berhubungan dengan munculnya kembali kejadian kaki gajah kabupaten Aceh Barat Tahun 2018

\begin{tabular}{|c|c|c|c|c|c|c|c|}
\hline \multirow{3}{*}{ Variabel Indepeden } & \multicolumn{4}{|c|}{ Kejadian Kaki Gajah } & \multirow{3}{*}{ OR } & \multirow{3}{*}{ CI } & \multirow{3}{*}{ P value } \\
\hline & \multicolumn{2}{|c|}{ Kasus } & \multicolumn{2}{|c|}{ Kontrol } & & & \\
\hline & $\mathbf{f}$ & $\%$ & $\mathbf{f}$ & $\%$ & & & \\
\hline \multicolumn{8}{|l|}{ Jenis Kelamin } \\
\hline Laki-laki & 7 & 46,67 & 20 & 44,44 & 1,12 & $0,29-4,21$ & 0,866 \\
\hline Perempuan & 8 & 53,33 & 25 & 55,56 & & & \\
\hline Jumlah & 15 & 100 & 45 & 100 & & & \\
\hline \multicolumn{8}{|l|}{ Pengetahuan } \\
\hline Kurang Baik & 11 & 73,33 & 16 & 35,56 & 4,1 & $1,23-14,04$ & 0,021 \\
\hline Baik & 4 & 26,67 & 29 & 64,44 & & & \\
\hline Jumlah & 15 & 100 & 45 & 100 & & & \\
\hline \multicolumn{8}{|l|}{ Sikap } \\
\hline Negatif & 10 & 66,67 & 16 & 35,56 & 3,6 & $1,04-12,79$ & 0,042 \\
\hline Positif & 5 & 33,33 & 29 & & & & \\
\hline Jumlah & 15 & 100 & 45 & 100 & & & \\
\hline \multicolumn{8}{|l|}{ Tindakan } \\
\hline Kurang baik & 7 & 46,67 & 8 & 17.78 & 6,2 & $1,21-32,15$ & 0,028 \\
\hline Baik & 8 & 53,33 & 37 & 82,22 & & & \\
\hline Jumlah & 15 & 100 & 45 & 100 & & & \\
\hline
\end{tabular}




\begin{tabular}{|c|c|c|c|c|c|c|c|}
\hline \multirow{3}{*}{ Variabel Indepeden } & \multicolumn{4}{|c|}{ Kejadian Kaki Gajah } & \multirow{3}{*}{ OR } & \multirow{3}{*}{ CI } & \multirow{3}{*}{ P value } \\
\hline & \multicolumn{2}{|c|}{ Kasus } & \multicolumn{2}{|c|}{ Kontrol } & & & \\
\hline & $\mathbf{f}$ & $\%$ & $\mathbf{f}$ & $\%$ & & & \\
\hline \multicolumn{8}{|l|}{ Literasi Kesehatan } \\
\hline Kurang Baik & 7 & 46,47 & 9 & 20 & 1,18 & $0,37-3,69$ & 0,773 \\
\hline Baik & 8 & 53,33 & 36 & 80 & & & \\
\hline Jumlah & 15 & 100 & 45 & 100 & & & \\
\hline \multicolumn{8}{|l|}{ Sosialisasi } \\
\hline Kurang Baik & 10 & 66,67 & 8 & 17,78 & 11,2 & $2,39-53,25$ & 0,002 \\
\hline Baik & 5 & 33,33 & 37 & 82,22 & & & \\
\hline Jumlah & 15 & 100 & 45 & 100 & & & \\
\hline \multicolumn{8}{|l|}{$\begin{array}{l}\text { Lingkungan fisik } \\
\text { rumah }\end{array}$} \\
\hline $\begin{array}{l}\text { Tidak Memenuhi } \\
\text { Syarat }\end{array}$ & 14 & 93,33 & 15 & 33,33 & 11,2 & $2,39-53,25$ & 0,002 \\
\hline Memenuhi Syarat & 1 & 6,67 & 30 & 66,67 & & & \\
\hline Jumlah & 15 & 100 & 45 & 100 & & & \\
\hline
\end{tabular}

Sumber: Data diolah tahun 2018

Tabel 3 menunjukkan bahwa ada beberapa faktor yang berhubungan dengan kejadian penyakit kaki gajah diantaranya: pengetahuan $\mathrm{OR}=4,1 \quad(\mathrm{CI} \quad 1,23-14,04)$ artinya responden yang memiliki pengetahuan kurang baik 4 kali berisiko kejadian penyakit kaki gajah dengan $p$ value 0,021, Sikap OR=3,6 (CI 1,04-12,79) artinya responden yang memiliki sikap negatif 3 kali beresiko kejadian penyakit kaki gajah dengan $p$ value 0,042 , Tindakan $\mathrm{OR}=6,2(\mathrm{CI} 1,21-32,15)$ artinya responden yang memiliki tindakan pencegahan kurang baik 6 kali berisiko kejadian penyakit kaki gajah dengan $p$ value 0,028 , sosialisasi OR
$=11,2(\mathrm{CI} 2,39-53,25)$ artinya responden yang mendapatkan sosialisasi kurang baik dari petugas kesehatan 11 kali berisiko kejadian penyakit kaki gajah dengan $p$ value 0,002, dan lingkungan fisik rumah OR 11,2 (CI 2,39-53,25) artinya responden dengan lingkungan fisik rumah tidak memenuhi syarat 11 kali berisiko kejadian penyakit kaki gajah dengan $p$ value 0,002 .

\section{ANALISIS MULTIVARIAT}

Dilakukan untuk mencari peluang faktor apakah yang paling dominan dengan munculnya kembali penyakit kaki gajah di Kabupaten Aceh Barat tahun 2018 dengan menggunakan regresi logistik. 
Tabel 4. Variabel yang dimasukkan ke dalam uji multivariat

\begin{tabular}{lllc}
\hline \multicolumn{1}{c}{ Variabel } & Odds Ratio & p-value & Confidence Interval \\
\hline Pengetahuan & 4,16 & 0,021 & $1,23-14,04$ \\
Sikap & 3,65 & 0,042 & $1,04-12,79$ \\
Tindakan & 6,24 & 0,028 & $1,21-32,15$ \\
Lingkungan fisik rumah & 11,2 & 0,002 & $2,39-53,25$ \\
Sosialisasi tenaga kesehatan & 11,28 & 0,002 & $2,39-53,25$ \\
\hline
\end{tabular}

Tabel 5. Kondisional logistik regresi faktor yang paling dominan dengan munculnya kembali penyakit kaki gajah di Kabupaten Aceh Barat tahun 2018

\begin{tabular}{llll}
\hline \multicolumn{1}{c}{ Variabel } & Odds Ratio & p-value & \multicolumn{1}{c}{ Confidence Interval } \\
\hline Pengetahuan kurang baik & 13,95 & 0,019 & $1,54-116$ \\
Sikap kurang baik & 1,12 & 0,920 & $1,07-7,51$ \\
Tindakan kurang baik & 28,60 & 0,049 & $1,01-12,40$
\end{tabular}

Berdasarkan Tabel 5. menunjukkan bahwa variabel yang signifikan yaitu pengetahuan kurang baik dengan nilai $\mathrm{p}=$ 0,019 dengan (CI 1,54-116) dan tindakan yang kurang baik merupakan faktor dominan dengan nilai $\mathrm{OR}=28,60$ memiliki makna bahwa tindakan yang kurang baik 28 kali berpeluang munculnya kembali penyakit kaki gajah dari pada variabel lain di kabupaten Aceh Barat tahun 2018, secara statistik memiliki hubungan yang signifikan dengan nilai $\mathrm{p}=0,049$

\section{PEMBAHASAN}

\section{a. Jenis Kelamin}

Hasil penelitian menunjukkan bahwa proporsi responden dengan jenis kelamin perempuan pada kelompok kasus 55,56\% lebih besar dari pada kelompok kasus sebesar 53,33\%, sedangkan proporsi responden jenis kelamin laki-laki pada kasus 46,67\%, lebih besar dari pada kelompok kontrol 44,44\%. Nilai OR $=1,12$ yang bermakna bahwa jenis kelamin lakilaki 1 kali lebih berpeluang terkena penyakit kaki gajah dari pada jenis kelamin perempuan akan tetapi dari statistik menunjukkan tidak ada hubungan yang signifikan antara jenis kelamin dengan munculnya kembali penyakit kaki gajah di Kabupaten Aceh Barat tahun 2018 dengan nilai $\mathrm{P}=0,866$.

Hasil penelitian yang dilakukan tentang faktor-faktor yang berhubungan dengan kejadian filariasis di Puskesmas Tirto Kabupaten Pekalongan, diketahui bahwa jenis kelamin menunjukan $\mathrm{p}$ value $1,000 \mathrm{OR}=1,24$ dengan $95 \% \mathrm{Cl}=0,365$ 3,974 yang artinya tidak ada hubungan antara jenis kelamin dengan kejadian filariasis dan jenis kelamin bukan merupakan faktor risiko kejadian filariasis. ${ }^{15}$ 
Semua jenis kelamin dapat terinfeksi mikrofilaria. Insiden kaki gajah pada lakilaki lebih tinggi daripada insiden filariasis pada perempuan karena umumnya laki-laki lebih sering kontak dengan vektor karena pekerjaannya tetapi pada zaman sekarang seorang perempuan juga sudah banyak bekerja membantu suami, hal itu terjadi di masyarakat Aceh Barat, para istri ikut bekerja di luar rumah untuk membantu suami seperti menyadap karet, mencari kayu dan madu di hutan, menjadi petani dll sehingga perempuan dan lelaki sekarang sama-sama rentan digigit nyamuk yang dapat menyebabkan penyakit kaki gajah

\section{b. Pengetahuan}

Hasil penelitian menunjukkan bahwa proporsi responden yang berpengetahuan baik pada kelompok kontrol sebesar 64,44\% lebih besar dari pada responden kelompok kasus 26,67\%, nilai $\mathrm{OR}=4,984$ yang maknanya responden yang pengetahuanya kurang baik hampir 5 kali lebih besar berisiko terkena penyakit kaki gajah dibandingkan dengan responden yang memiliki pengetahuan baik dan secara statistik adanya hubungan yang signifikan antara pengetahuan dengan munculnya kembali penyakit kaki gajah di Kabupaten Aceh Barat tahun 2018 dengan nilai $\mathrm{p}=$ 0,015 .

Hasil penelitian yang dilakukan tentang faktor-faktor yang berhubungan dengan kejadian filariasis di Puskesmas Tirto I Kabupaten Pekalongan, menunjukkan bahwa pengetahuan menujukan $p$ value $0,041 \mathrm{OR}=3,5$ dengan $95 \% \mathrm{Cl}=1,05-12,4$ yang berarti ada hubungan pengetahuan dengan kejadian filariasis dan merupakan faktor risiko kejadian filariasis. ${ }^{15}$

Masyarakat harus rutin atau sering diberikan edukasi oleh petugas kesehatan baik melalui promosi kesehatan maupun penyuluhan yang difokuskan pada langkahlangkah pengobatan yaitu mengkosumsi obat, mengoleskan krim anti bakteri pada bagian organ yang membengkak, serta sering terapi dengan cara mengerakkan organ tubuh yang sudah membengkak akibat filaria sehingga mereka mengerti bahwasanya penyakit filariasis bukan penyakit kutukan melainkan penyakit menular yang bisa dicegah dengan menghindari sedapat mungkin dari gigitan nyamuk bahkan penyakit ini bisa diobati

\section{c. Sikap}

Hasil penelitian menunjukkan bahwa proporsi responden yang memiliki sikap positif pada kelompok kontrol sebesar 64,44\% lebih besar dibandingkan dengan responden pada kelompok kasus sebesar $33,33 \%$, sedangkan proporsi responden yang memiliki sikap negatif pada kelompok kasus $66,67 \%$ lebih besar dibandingkan dengan responden pada kelompok kontrol 
sebesar $35,56 \%$. Nilai OR $=3,65$ yang bermakna responden yang memiliki sikap negatif 3 kali beresiko terkena penyakit filariasis dari pada responden yang memiliki sikap positif dan secara statistik juga menunjukkan ada hubungan yang signifikan antara sikap dengan munculnya kembali penyakit kaki gajah di Kabupaten Aceh Barat tahun 2019 dengan $\mathrm{P}=0,042$.

Studi mengungkapkan bahwa ada hubungan yang signifikan antara sikap dengan filariasis dengan nilai $\mathrm{p}(0,046) .{ }^{16}$ Pembentukkan sikap dipengaruhi oleh beberapa faktor yaitu pengalaman pribadi, kebudayaan, media massa, lembaga pendidikan dan agama. ${ }^{17}$

Sikap tidak ada hubungan dengan kejadian kaki gajah dikarenakan banyak masyarakat di Aceh Barat yang menentukan sikap positif tetapi di sisi lain mayarakat juga mempunyai stigma bahwa filariasis adalah penyakit kutukan Hal ini membuat sikap mereka terhadap kasus filariasis menjadi ambigu, sehingga tidak berbanding lurus dengan tindakan yang mereka lakukan.

Masyarakat harus diberikan edukasi tentang penyakit kaki gajah dan ikut berperan bersama pemerintah untuk menjaga lingkungan sehingga dapat mencegah penyakit kaki gajah karena selama ini masyarakat di Aceh Barat sangat sedikit mempunyai sikap positif untuk mendukung pemberantasan sarang nyamuk bersama-sama dengan pemerintah.

\section{d. Tindakan Pencegahan}

Hasil penelitian menunjukkan bahwa proporsi responden yang memiliki tindakan baik pada kelompok kontrol sebesar $82,22 \%$ lebih besar dibandingkan dengan responden pada kelompok kasus sebesar $53,33 \%$, nilai $\mathrm{OR}=6,24$ yang bermakna bahwa responden yang tindakkannya kurang baik 6 kali berpeluang terkena penyakit kaki gajah dibandingkan dengan responden yang tindakannya baik, secara statistik juga menunjukkan adanya hubungan yang signifikan antara tindakan dengan munculnya kembali penyakit kaki gajah di Kabupaten Aceh Barat tahun 2018 dengan $p$-value $=0,028$.

Pemerintah maupun petugas kesehatan sebaiknya mempromosikan atau memperlihatkan pada masyarakat tindakan pencegahan filariasis baik menggunakan media elektronik maupun secara langsung. Hal ini membuat masyarakat cenderung ikut melakukan karena pemimpin atau petugas kesehatan bisa menjadi panutan atau roll model bagi masyarakat, yang selama ini sangat sedikit ikut berpartisipasi dalam pemberantasan sarang nyamuk. Selain itu petugas kesehatan memotiviasi masyarakat untuk mengkomsumsi obat karena tingkat konsumsi obat pada masyarakat tergolong rendah. 


\section{e. Literasi kesehatan}

Hasil penelitian menunjukkan proporsi responden yang memiliki literasi kesehatan baik tidak terpapar penyakit kaki gajah sebesar $80 \%$ lebih besar dibandingkan dengan responden yang terpapar penyakit kaki gajah sebesar 53,33\%, sedangkan proporsi responden yang memiliki literasi kesehatan kurang baik terpapar penyakit kaki gajah sebesar 46,67\% lebih besar dibandingkan dengan responden yang tidak terpapar penyakit kaki gajah sebesar $20 \%$.

Nilai $\mathrm{OR}=1,18$ yang bermakna bahwa responden yang literasinya kurang baik 1 kali berpeluang terkena penyakit kaki gajah dibandingkan dengan responden yang literasinya baik, secara statistik juga menunjukkan tidak ada hubungan yang signifikan antara literasi kesehatan dengan munculnya kembali penyakit kaki gajah di Kabupaten Aceh Barat tahun 2018 dengan nilai $\mathrm{P}=0,773$.

Literasi merupakan suatu proses yang hasilnya adalah pengetahuan, literasi tidak hanya masalah tahu dan tidak tahu melainkan juga memahmi, banyak masyarakat yang tahu tentang penyakit kaki gajah akan tetapi banyak juga yang tidak memahami sehingga masyarakat menjadi bingung harus melakukan apa untuk mencegah penyakit kaki gajah di lingkungannya sendiri, literasi yang kurang baik membuat masyarakat salah menilai sehingga stigma yang berkembang di masyarakat bahwa penyakit kaki gajah adalah penyakit kutukan membuat sebagian menjadi pasrah tanpa berusaha mencari pengobatan medis.

\section{f. Sosialisasi petugas kesehatan}

Hasil penelitian menunjukkan bahwa proporsi responden yang mendapatkan sosialisasi baik dari petugas kesehatan pada kelompok kontrol sebesar 82.22\% lebih besar dibandingkan dengan responden pada kelompok kasus sebesar 33.33\%, sedangkan proporsi responden yang mendapatkan sosialisasi kurang baik dari tenaga kesehatan pada kelompok kasus sebesar $66.67 \%$ lebih besar dibandingkan dengan responden pada kelompok kontrol sebesar $17.78 \%$. nilai $\mathrm{OR}=11.2$ yang bermakna bahwa responden yang mendapatkan sosialisasi kurang baik dari tenaga kesehatan 11 kali berpeluang terkena penyakit kaki gajah dibandingkan dengan responden yang mendapatkan sosialisasi dengan baik oleh tenaga kesehatan, secara statistik juga Menunjukkan bahwa adanya hubungan yang signifikan antara sosialisasi dengan munculnya kembali penyakit kaki gajah di Kabupaten Aceh Barat tahun 2018 dengan nilai $\mathrm{p}=0,002$.

Salah satu dukungan dari petugas adalah dengan adanya sosialisasi dari petugas kesehatan mengenai pemberian obat massal pencegah filariasis. Petugas 
yang tidak ada mensosialisasikan ke masyarakat atau kurang memotivasi masyarakat akan mengakibatkan rendahnya cakupan menelan obat filariasis pada masyarakat. $^{18}$

Sosialisasi dibutuhkan untuk peningkatan pengetahuan masyarakat tentang penyakit filariasis sehingga meningkatkan kesadaran masyarakat dalam upaya pencegahan penyakit melalui pengobatan massal dan proteksi diri dari gigitan nyamuk khususnya di daerah dengan endemisitas dan tingkat penyebaran penyakit yang tinggi dan masyarakat mampu menyikapi dengan benar apabila terjadi reaksi dalam pengobatan.

Pemerintah melalui dinas kesehatan harus gencar memberikan sosialisasi pengobatan filariasis juga harus memperhatikan dan menyiapkan petugas kesehatan yang terbaik di bidang ini, di Aceh Barat banyak petugas hanya membagikan obat tanpa diberikan arahan dan edukasi kepada masyarakat sehingga pemberian obat filariasis terkesan seperti pembagian sembako, selain itu dalam internal bidang seksi pencegahan pengobatan penyakit juga harus merangkul bidang lain seperti promkes dalam program pengobatan filariasis sehingga mencapai target nasional yakni 80 persen, saat ini di Aceh Barat distribusi obat hanya 60 persen.

\section{g. Lingkungan fisik rumah}

Hasil penelitian menunjukkan bahwa proporsi responden yang memiliki lingkungan fisik rumah memenuhi syarat pada kelompok kontrol sebesar $66,67 \%$ lebih besar dibandingkan dengan responden pada kelompok kasus sebesar 6,67\%, sedangkan proporsi responden yang memiliki lingkungan fisik rumah tidak memenuhi syarat pada kelompok kasus sebesar 93,33\% lebih besar dibandingkan dengan responden pada kelompok kontrol sebesar $33,33 \%$. nilai $\mathrm{OR}=11,28$ yang bermakna bahwa responden yang lingkungan fisik rumah tidak memenuhi syarat 11 kali berpeluang terkena penyakit kaki gajah dibandingkan dengan responden yang lingkungan fisik rumahnya memenuhi syarat, secara statistik juga menunjukkan adanya hubungan yang signifikan antara lingkungan fisik rumah dengan munculnya kembali penyakit kaki gajah di Kabupaten Aceh Barat dengan nilai $\mathrm{p}=0,002$.

Faktor lingkungan merupakan salah satu yang mempengaruhi kepadatan vektor filariasis. Lingkungan ideal bagi nyamuk dapat dijadikan tempat potensial untuk perkembangbiakan dan peristirahatan nyamuk sehingga kepadatan nyamuk akan meningkat. ${ }^{19}$ Faktor lingkungan yang mempengaruhi kepadatan vektor filariasis adalah lingkungan fisik, lingkungan 
biologik serta lingkungan sosial dan ekonomi. ${ }^{20}$

Faktor lingkungan biologik meliputi tanaman air dan semak-semak. Keberadaan lingkungan biologik maupun fisik erat kaitannya dengan bionomik vektor filariasis. Faktor lingkungan yang mendukung keberadaan vektor filariasis dapat menjadi faktor risiko penularan filariasis. $^{20}$

Lingkungan sangat besar hubungan atau pengaruhnya dengan kejadian kaki gajah dikarenakan lingkungan yang kurang baik bisa dimanfaatkan oleh nyamuk untuk dijadikan tempat perindukan. ${ }^{21}$ Aceh Barat sendiri banyak lingkungan yang sudah rusak menjadi rawa-rawa atau semak-semak di sekitar rumah penduduk ditambah lagi masyarakat kurang menjaga lingkungan rumah seperti pemasangan kawat kasa, membuat saluran pembuangan sesuai standar sehingga masyarakat sangat sering terjadi kontak langsung dengan nyamuk.

Pemerintah melaui jalur politik harus memperjuangkan masyarakatnya melawan pabrik atau industri yang terkesan membuang limbah sembarangan yang berdampak langsung ke perumahan penduduk, pemerintah juga harus memperhatikan infrastruktur di lingkungan perumahan yang direlokasikan akibat tsunami, masih banyaknya rumah masyarakat yang tidak ada saluran pembuangan air limbah dirumahnya bahkan saluran pembuangan yang telah dibuat pemerintah tidak berfungsi dengan baik, dalam penelitian selain masyarakat peran pemerintah sangat strategis dalam menjaga lingkungan bahkan berperan besar merangkul masyarakat untuk menghidupkan kembali semangat gotong royong yang dulu pernah diberlakukan dalam seminggu sekali. ${ }^{22}$

\section{KESIMPULAN}

Berdasarkan hasil penelitian yang dilakukan di wilayah Kecamatan Aceh Barat terhadap 60 responden, faktor yang memiliki hubungan signifikan dengan munculnya kembali penyakit kaki gajah di Kabupaten Aceh Barat yaitu pengetahuan $(\mathrm{p}=0,021, \quad \mathrm{OR}=4,16), \quad$ sikap $\quad(\mathrm{p}=0,042$, $\mathrm{OR}=3,65)$, tindakan $(\mathrm{p}=0,028, \mathrm{OR}=6,24)$, Sosialisasi tenaga kesehatan $(\mathrm{p}=0,002$, $\mathrm{OR}=11,2)$ dan lingkungan fisik rumah $(\mathrm{p}=0,002, \quad \mathrm{OR}=11,28), \quad$ serta tidak ada hubungan antara jenis kelamin $(p=0,866$, $\mathrm{OR}=1,21)$, literasi kesehatan $\quad(\mathrm{p}=0,773$, $\mathrm{OR}=1,18$ ), dengan munculnya kembali penyakit kaki gajah di Kabupaten Aceh Barat tahun 2019.

Setelah dilakukan uji multivariat untuk melihat faktor yang paling dominan maka variabel tindakan merupakan faktor yang dominan sebesar 28 kali berpeluang munculnya kembali penyakit kaki gajah lebih besar dibandingkan dengan variabel lain. Variabel sosialisasi dan lingkungan 
fisik rumah dikeluarkan dalam analisis multivariat karena menganggu/ mempengaruhi variabel lain. Variabel literasi kesehatan yang merupakan variabel baru dalam penelitian ini dan tidak memiliki hubungan yang signifikan dengan munculnya kembali penyakit kaki gajah di Kabupaten Aceh Barat.

\section{SARAN}

Bagi masyarakat disarankan tidak bekerja pada malam hari di luar rumah jika itu memungkinkan, apabila bekerja di luar rumah pada malam hari disarankan memakai pakaian yang menutupi seluruh bagian tubuh agar terhindar dari gigitan nyamuk bagi masyarakat khususnya responden disarankan juga untuk mengkonsumsi obat pencegahan penyakit kaki gajah.

Puskesmas diharapkan dapat melakukan penyuluhan secara teratur tentang filariasis guna meningkatkan pengetahuan masyarakat tentang faktor yang dapat berisiko tertular filariasis. Mengoptimalkan sumber informasi yang digemari masyarakat untuk mendapatkan informasi kesehatan sesuai dengan sosial budaya seperti bahasa, media dan cara penggunaannya.

Dinas Kesehatan Kabupaten Aceh Barat diharapkan membuat suatu media informasi yang menarik tentang pencegahan kaki gajah seperti leaflet atau poster yang dipasang di tempat-tempat umum di desa dan tempat strategis lainnya, seperti papan informasi, pos siskamling dan balai desa.

\section{UCAPAN TERIMA KASIH}

Terima kasih kepada pembimbing tesis yang telah membimbing dengan sabar dan mengorbakan waktu dengan tujuan penelitian ini bisa bermanfaat untuk masyarakat dan terima kasih kepada Dinas Kesehatan Aceh Barat yang telah melaksanakan pengumpulan informasi mengenai kejadian Filariasis. dan telah menfasilitasi data survei sehingga bisa diakses.

\section{DAFTAR PUSTAKA}

1. Komaria RH, Faisya H. F, Sunarsih E. Analysis of Physical Environment and Preventive Behavior Determinants Toward Genesis Filariasis Cases in the Sub-district of Talang Kelapa and Sembawa, District of Banyuasin. 2016;7.

2. Riftiana $\mathrm{N}$ dan S. Hubungan sosiodemografi dengan kejadian filariasis di Kabupaten Pekalongan. Kes Mas UAD. 2010;4(1):59-65. doi:10.12928/kesmas.v4i1.1103

3. Arsin AA. Epidemiologi Filariasis Di Indonesia; 2016. Makasar: Masagena Press Makassar; 2016.

4. Afra D, Harminarti N. Faktor-faktor yang berhubungan dengan kejadian filariasis di Kabupaten Padang Pariaman tahun 2010-2013. J Kesehat Andalas. 2013;5(1):111-119.

5. Kementerian Kesehatan. Rencana Nasional Program Akselerasi Eliminasi Filariasis Di Indonesia. Jakarta: Subdit Filariasis \& Schistomiasis Direktorat P2B2, Ditjen PP\&PI; 2010; 2010. 
6. Kementerian Kesehatan Republik Indonesia. Peraturan Menteri Kesehatan Repubik Indonesia Nomor 94 Tahun $2014 \quad$ Tentang Penanggulangan Filariasis.; 2014:1118. doi:10.1371/jour

7. Depkes RI. Epidemiologi Penyakit Kaki Gajah (Filariasis) Di Indonesia. Jakarta: Dirjen PPM \& PL; 2006.

8. Syuhada Y, Nurjazuli, W NE. Studi Kondisi Lingkungan Rumah dan Perilaku Masyarakat Sebagai Faktor Risiko Kejadian Filariasis di Kecamatan Buaran dan Tirto Kabupaten Pekalongan ( Study Of Environmental And Behavioral As Risk Factor Of Filariasis In District Of Buaran And Tirto Pekalo. Kesehat Lingkung Indones. 2012;11(1):95-101.

file://G:/PROPOSAL/4147-8895-1-

SM (1).pdf.

9. Notoatmodjo S. Promosi Kesehatan Teori Dan Aplikasi, Jakarta: Rineka Cipta, 2005:52-54. Jakarta: Rineka Cipta; 2005.

10. Soetomo F, Colver GM, Forouraghi $\mathrm{K}$. Micro-force measurement of drag on a small flat plate in the presence of a corona discharge. $J$ Electrostat. 2006;64(7-9):525-530.

doi:10.1016/j.elstat.2005.10.006

11. Santoso. Hubungan kondisi lingkungan dengan kasus filariasis di masyarakat (Analisis lanjut hasil Riskesdas 2007). Aspirator J Vector Borne Dis Stud. 2011;3(1):1-7. doi:10.22435/aspirator.v3i1.2953.

12. Ottesen EA. The Global Pl Programme to Eliminate Lymphatic Filariasis. Trop Med Int Heal. 2000;5(9):591-594.

doi:10.1046/j.13653156.2000.00620.x

13. Lapau B, Birwin A. Prinsip \& Metode Epidemiologi. Jakarta: FK UI; 2009.

14. Notoatmodjo S. Metodologi Penelitian Kesehatan. Jakarta:
Rineka Cipta; 2010.

15. Yanuarni C. Faktor-Faktor Yang Berhubungan Dengan Kejadian Filariasis Di Puskesmas Tirto I Kabupaten Pekalongan. Fikkes $J$ Keperawatan. 2015;8(1):73-86.

16. Ikawati B, Wijayanti T. Pengetahuan, Sikap, dan Praktik Masyarakat kelurahan Pabean, Kecamatan Pekalongan Utara, Kota Pekalongan tentang Filariasis Limfatik. Ekol Kesehat. 2010;9:1324-1332.

17. Azwar S. Sikap Manusia: Teori Dan Pengukurannya. Yogyakarta: Yogyakarta: Pustaka Pelajar; 2013.

18. Ipa M, Astuti EP, Hakim L, Fuadzy H. Analisis Cakupan Obat Massal Pencegahan Filariasis di Kabupaten Bandung dengan Pendekatan Model Sistem Dinamik Analysis of Filariasis Mass Drug Administration Coverage Through Dynamic System Model in Bandung Regency. 2016:31-38.

19. Salim MF, Baskoro $\mathrm{T}$, Satoto $\mathrm{T}$, Kusnanto H. Zona Kerentanan Filariasis Berdasarkan Faktor Risiko dengan Pendekatan Sistem Informasi Geografis. J Inf Syst Public Heal. 2016;1(1):16-24.

20. Dirjen PP \& PL. Pedoman Program Eliminasi Filariasis Di Indonesia. Jakarta: Kementerian Kesehatan RI; 2009.

21. Pulungan ES, Santi DN, Chahaya I. Hubungan Sanitasi Lingkungan Perumahan dan Perilaku Masyarakat dengan Kejadian Filariasis di Kecamatan Kampung Rakyat Kabupaten Labuhan Batu Selatan. Lingkung dan Keselam Kerja. 2013;2(1):1-10.

22. Erlan A. Promosi kesehatan dalam pengendalian filariasis. Balaba. 2014;10(02):89-96.

http://ejournal.litbang.depkes.go.id/in dex.php/blb/article/viewFile/3691/36 17. 
SEL Jurnal Penelitian Kesehatan Vol. 6 No.2, November 2019, 75-89 